\title{
Comparison of Mechanical Performance of Hybrid Viny- based Composites reinforced with Coir/Sisal and Sisal/Kenaf Fibres
}

\author{
T. Gopinathan \\ Department of Mechanical Engineering, \\ Kongu Engineering College, \\ Erode, Tamilnadu, India
}

\author{
R. Deepak Kumar \\ Department of Mechatronics Engineering \\ Kongu Engineering College \\ Erode, Tamilnadu, India
}

\begin{abstract}
Considerable research in the field of material science has been directed towards the development of new light weight, high performance engineering materials like composite. In many applications, like an aircraft, there is a need for high strength weight ratio. This can be achieved by composite consisting of low density (and soft) matrix reinforced with stiff fibres. Now a day's attention has been focused in the development of natural fibre composite due to their low cost and easy renewability. In this investigation the mechanical properties of Hybrid fibre reinforced vinyl ester composites were analysed based on volume percentage and length of fibre ,similarly single natural fibre composite were developed to compare the properties. The tensile and impact strength increase with fibre length and fibre content, on the other hand flexural strength decrease with fibre length and content.
\end{abstract}

Keywords: Hybrid fibre composites; Vinyl ester; Mechanical properties; Regression models.

\section{INTRODUCTION}

In recent years, utilization of composite material in many engineering fields has undergone a tremendous increase. The background of the research that has been carried out is the awareness that the demand of coir, sisal and kenaf products is slowly decreasing and that other profitable markets have to be found for this commodity. The best way to bring the existing coir-sisal, kenaf industry to a higher level is the development of new coir sisal and kenaf products with higher added value of mechanical properties. One possible technology that could fulfil this goal is the use of coir-sisal fibre in composite components .Coir is a versatile lignocellulosic fibre obtained from coconut trees (Cocos nucifera), which grow extensively in tropical countries. Because of its hard wearing quality, durability and other advantages, it is used for making a wide variety of floor-furnishing materials, yarn, rope, etc. [1]. However, these traditional coir products consume only a small percentage of the total world production of coconut husk. Coir is a cheap fibre, even cheaper than sisal and jute [2]. Coir fibres are not as brittle as glass fibres, are amenable to chemical modification, are non-toxic and possess no waste disposal problems, but unfortunately the performance of coir as a reinforcement in polymer composites is unsatisfactory and not comparable even with other natural fibres. This inferior performance of coir is due to various factors such as its low cellulose content, high lignin content, high microfibrillar angle, and large as well as variable diameter. Sisal fibre is hard fibre extracted from the leaves of the sisal plant (Agave sisalana). Though native to tropical and subtropical North and South America, sisal plant is now widely grown in tropical countries of Africa, the West Indies and the Far East [3].
The effect of diameter, test length and test speed on the tensile strength, initial modulus and percent elongation at the break of sisal fibre is studied. They concluded that no significant variation of mechanical properties with change in fibre diameter was observed. However, the tensile strength and percent elongation at the break decrease while Young's modulus, increases with fibre length [4]. The optimum fibre parameters and their influence on the mechanical properties for coir-polyester resin were studied and the results are shown that the fibre content in weight percentage is playing major role than the fibre length on the improvement of tensile, flexural, and impact strength properties [5].Beside a number of investigations have been conducted on the natural fibre hybrid composite to study the effect of hybridisation of these fibre on the mechanical properties. The tensile strength of plain weave hybrid ramie-cotton fabrics polyester matrix composite was determined as a function of volume fraction and orientation of ramie fibre [6]. The dynamic properties such as storage modulus, damping behaviour and static mechanical properties such as tensile, flexural and impact of randomly oriented intimately mixed short banana/sisal hybrid fibre reinforced polyester composites a function of total investigated[7].The effect of concentration and modification of fibre surface in sisal/oil palm hybrid fibre reinforced rubber composites have been studied [8].Water absorption behaviour, the effect of temperature of immersion ,fibre volume fraction ,and three drying of fabrics before there incorporation and to the composite of sisal/cotton, jute/cotton and ramie/cotton hybrid fabric reinforced composite were evaluated [9].Statics and dynamics mechanical properties kenaf fibres and wood floor hybrid polypropylene composites were studied [10]. The optimum fibre parameters and their influence on the mechanical properties for coir-polyester resin were studied and the results are shown that the fibre content in weight percentage is playing major role than the fibre length on the improvement of tensile, flexural, and impact strength properties. Since most data in literature cover only a specific loading fraction of fibres, this work was aimed at analyzing 
the mechanical behaviour of hybrid fibre vinyl ester composites covering short fibre length and volume fractions.

\section{EXPERIMENTAL PROCEDURE}

\subsection{Materials}

\subsubsection{Coir}

Coir is lignocellulosic natural fibre. Its seed hair fibre obtained from outer shell, or husk of coconut, fruit of the cocus nusifera.The coarse, stiff, reddish, brown fibre made of small thread, each of about 0.03 to $0.1 \mathrm{~cm}$ long and 12 to $24 \mu \mathrm{m}$ in diameter composed of lignin, woody plant substance, and cellulose. The individual fibre are narrow, with thick walls made of cellulose. They are pale when immature but later hardened become yellowed as a layer of lignin on their walls.

\subsubsection{Sisal}

Sisal is another natural fibre obtained from the leaves of a plant. It is most produced natural fibre after cotton. Sisal, also known as sisal hemp is a plant that yields a stiff fibre and is mostly used for making rope. The fibre is smooth and straight and light yellow in colour. It is fairly coarse and it is extensively used because of its strength, durability, ability to stretch, affinity for certain dyestuffs, and resistance to deterioration in saltwater.

\subsubsection{Kenaf fibre}

Kenaf is one of the allied fibres of jute and shows similar characteristics. Other names include Bimli, AmbaryAmbari Hemp, Deccan Hemp, and Bimlipatum Jute. It is an annual or biennial herbaceouplant (rarely Short-lived perennial) growing to $1.5-3.5 \mathrm{~m}$ tall with a woody base. The stems are 1$2 \mathrm{~cm}$ diameter.

\subsubsection{Vinyl ester resin}

It's one of the Addition polymers. It acts as a good binder for fibre, excellent physical properties including good toughness and good impact properties. Curing time is also less compare to other resin. Vinyl ester combines inherent toughness with outstanding heat and chemical resistance, Corrosionresistance, and Possesses low ester content and low instauration resulting in greater resistance to hydrolysis and less shrinkage during cure. The Properties of vinyl ester is shown in Table 2.

The untreated natural fibre were cut for the dimensions of 10,20, and $30 \mathrm{~mm}$ length and fibre content in volume percentage of 20,30 , and 40 , respectively. The two parameters and three levels contributed total of nine combinations, and these combinations were planned using Design of Experiments. The simple hand lay-up process was followed for fabricating Hybrid-vinyl ester composites. The Properties of coir, sisal and kenaf is shown in Table 1

\begin{tabular}{|c|c|c|c|}
\hline \multicolumn{4}{|c|}{ Tablet hrepertine of cert and sisal } \\
\hline hoperties & $\cos$ & Sisat & eenat \\
\hline Cethose batsi| & $36-43$ & $67-78$ & $75-90$ \\
\hline Yourg's modibis (Gse) & 46 & $5 s-126$ & 35.40 \\
\hline Teste ssength (MPa) & $131-175$ & 488.400 & 350600 \\
\hline Lipun (wth) & 050.25 & 8-11 & 7- \\
\hline Denutvign/cm | & 1.35 & 1.33 & 3.5 \\
\hline \multicolumn{4}{|c|}{ Table? Propetitis of vayl sver } \\
\hline Frogen & & \multicolumn{2}{|c|}{ Viast-efter ain } \\
\hline Apperanas: & & \multicolumn{2}{|c|}{ Daik yellon tobnt } \\
\hline Wistoing(p) & & \multicolumn{2}{|c|}{800} \\
\hline 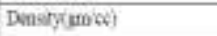 & & \multicolumn{2}{|c|}{1.19} \\
\hline Ebongroun it lireak $(9 \%$ & & \multicolumn{2}{|c|}{5} \\
\hline Tessik stretght(Mpoj & & \multicolumn{2}{|c|}{90} \\
\hline 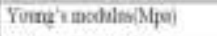 & & \multicolumn{2}{|c|}{090} \\
\hline 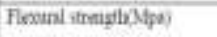 & & \multicolumn{2}{|c|}{$\$ 8$} \\
\hline 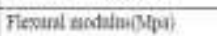 & & \multicolumn{2}{|c|}{2781} \\
\hline
\end{tabular}

Poly vinyl acetate release agent was applied to the surfaces before the mould. The fibres are proportionally mixed and were pre-impregnated with the matrix material consisting of unsaturated vinyl ester resin, promoter, cobalt octoate, accelerator, and MEKP catalyst. The impregnated layers were placed in the resin matrix $(18 \times 16 \mathrm{~cm})$ and pressed heavily for $1 \mathrm{~h}$ before removal. After $1 \mathrm{~h}$, the composites were removed from the mould and cured at room temperature for $24 \mathrm{~h}$. The same procedure was followed to prepare different types of composites as per the nine combinations of fibre parameters. The fabricated hybrid composite is shown in Figure1.

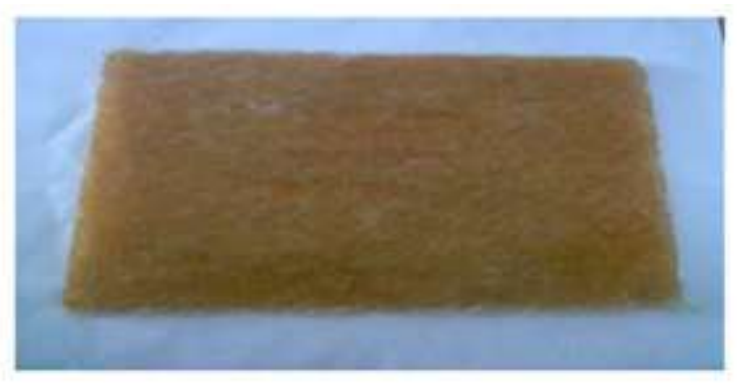

Figure1. Fabricated fibre composite.

\section{MECHANICAL TEST}

\subsection{Tensile test}

The tensile test is generally performed on flat specimens. The commonly used specimen for tensile test is the dog-bone specimen with end tabs. Test conducted by Tensometer testing machine (force range-up to $20 \mathrm{KN}$,cross head travel-525mm excluding grip ,testing length-135mm between the grip, dc servometer-1,1Nm, controller-digital load and extension microprocessor)and cross-head speed of $5 \mathrm{~mm} / \mathrm{min}$ as per ASTM D638-08. The tensile test specimen before and after testing is shown in Figure 2. The length, width, and thickness of each sample were approximately 165,25 , and $3 \mathrm{~mm}$, respectively and results are analyzed to calculate the tensile strength of composites samples. 


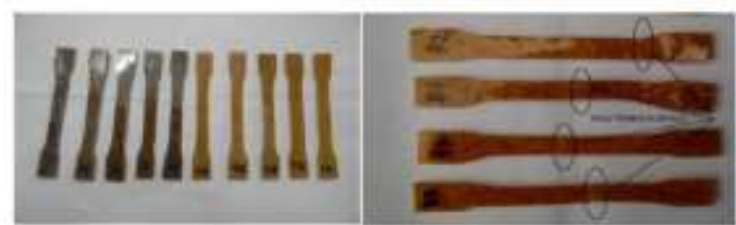

Figure 2. Tensile Specimen before and after testing.

\subsection{Flexural strength}

The flexural strength of a composite is the maximum tensile stress that it can withstand during bending before reaching the breaking point. The rectangular test pieces of $12.7 \times 12.7 \times 3$ $\mathrm{mm}$ dimension for flexural test were cut from the prepared Hybrid composite. Flexural test was conducted as per ASTMD790-07. The flexural test specimen while and after testing is shown in Figure 3. The three point bend test is conducted on all the composite samples in the universal testing machine Instron1195, cross head speed of $10 \mathrm{~mm} / \mathrm{min}$ are maintained.

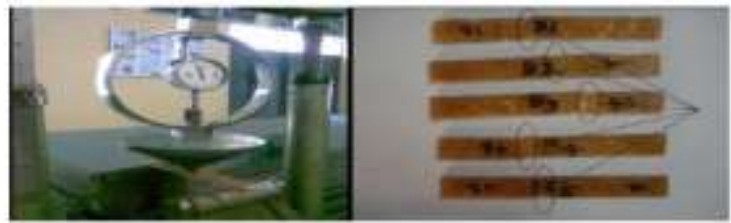

Figure 3. Flexural specimen while and after testing.

\subsection{Impact strength}

The impact strength of the samples was measured using ATS FAAR Impact tester (model No. 16.1 and capacity of up to 25 J) as per ASTMD256-06 standards. The test specimen was supported as a vertical cantilever beam and broken by a single swing of a pendulum. The pendulum strikes the face of the sample and total of five samples were tested and the mean value of the absorbed energy was taken. The impact test specimen before and after testing is shown in Figure 4.

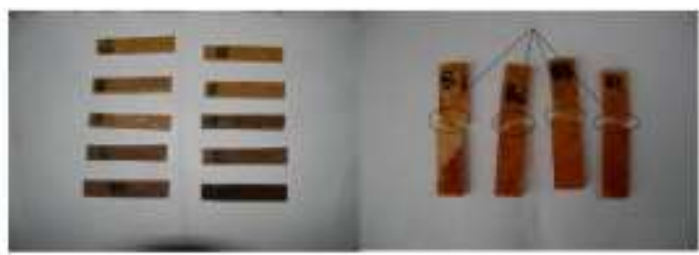

Figure 4. Impact specimen before and after testing.

\section{RESULTS AND DISCUSSION}

\subsection{Effect of length and fibre content in coir composite}

Importance of mechanical analysis as a main tool in study of performance of natural fibre polymer composite is a paramount of importance. Mechanical properties of fibre reinforced composite depend on polymeric matrix, distribution and orientation of reinforcing fibre, nature of fibre-matrix interface and interface region. The coir vinylester composite exhibited maximum tensile strength of 17.40MPa for the fibre length of $30 \mathrm{~mm}$ and fibre volume content of $40 \%$. The increase of fibre length value and fibre content increase the tensile properties .The fibre length of $30 \mathrm{~mm}$ and fibre volume content $20 \%$ vol exhibited maximum flexural strength of $38.5 \mathrm{MPa}$. Increase the fibre content flexural strength start decreasing and impact behaviour of $162.84 \mathrm{~J} / \mathrm{m}$ for the fibre length of $30 \mathrm{~mm}$ and fibre content of $40 \%$. Increase the fibre length and fibre content increase impact properties. The effect of length and fibre content in coir composite is shown in Figure 5

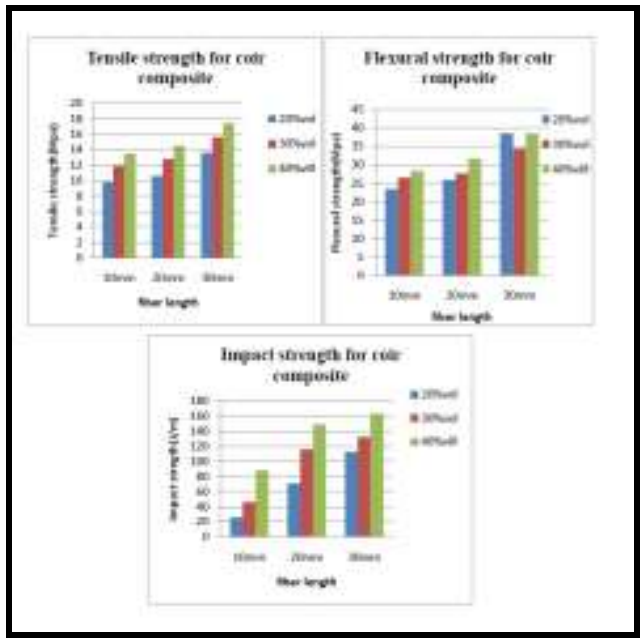

Figure 5. Effect of length and fibre content on coir composite.4.2 Effect of length and fibre content in coir/sisal composite

The coir/sisal vinyl-ester composite exhibited maximum tensile strength of $20.1 \mathrm{MPa}$ for the fibre length of $30 \mathrm{~mm}$ and fibre volume content of $40 \%$. The increase of fibre length value and fibre content increase the tensile properties .The fibre length of $30 \mathrm{~mm}$ and fibre volume content $20 \% \mathrm{vol}$ exhibited maximum flexural strength of $39.4 \mathrm{MPa}$.increase the fibre content flexural strength start decreasing and impact behaviour of $170 \mathrm{~J} / \mathrm{m}$ for the fibre length of $30 \mathrm{~mm}$ and fibre content of $40 \%$.increase the fibre length and fibre content increase impact properties. The effect of length and fibre content in coir/sisal composite is shown in Figure 6.

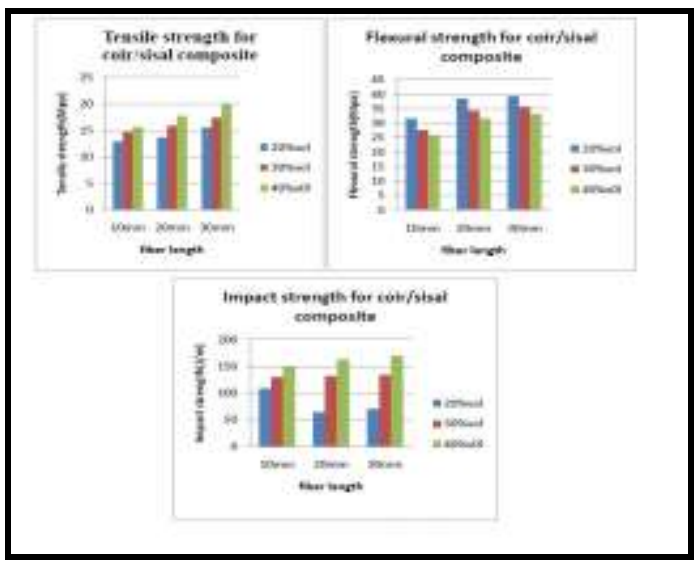

Figure 6. Effect of length and fibre content in coir/sisal composite. 


\subsection{Effect of length and fibre content in sisal/kenaf composite}

The sisal/kenaf vinyl-ester composite exhibited maximum tensile strength of $22.1 \mathrm{MPa}$ for the fibre length of $30 \mathrm{~mm}$ and fibre volume content of $40 \%$. The increase of fibre length value and fibre content increase the tensile properties .The fibre length of $30 \mathrm{~mm}$ and fibre volume content $20 \% \mathrm{vol}$ exhibited maximum flexural strength of 43.4MPa.increase the fibre content flexural strength start decreasing and impact behaviour of $172.84 \mathrm{~J} / \mathrm{m}$ for the fibre length of $30 \mathrm{~mm}$ and fibre content of $40 \%$.increase the fibre length and fibre content increase impact strength. The effect of length and fibre content in sisal/kenaf composite is shown in Figure 7.

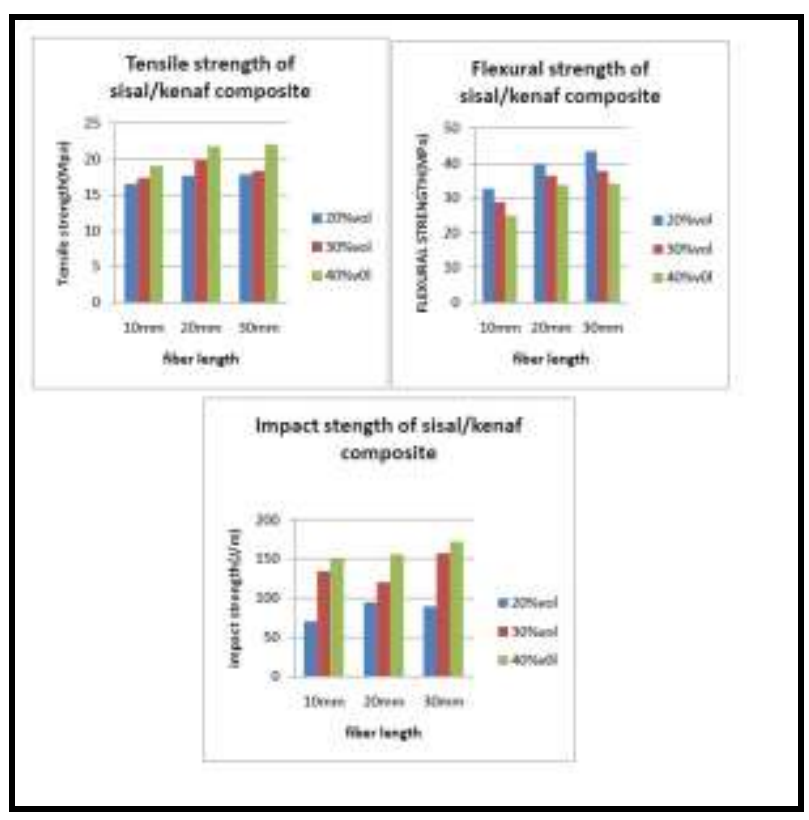

Figure 7 Effect of length and fibre content in sisal/kenaf composite

\section{CONCLUSIONS}

The investigation originally aimed at improvement of mechanical properties of natural fibre and replacement of glass fibre. The investigation reported that increase the fibre length and fibre content increase the tensile and impact properties but lowered the flexural strength. High tensile strength, flexural strength and impact strength reinforced with sisal/kenaf composite compared with coir and coir/sisal reinforcement. Hybridisation improve over all mechanical properties. The result hybrid vinyl ester composite with correct or optimum weight and correct length of fibres give the expected performance.

\section{REFERENCES}

[1] Satyanarayana KG, Kulkarni AG, Rohatgi PK. Structures and properties of some vegetable fibres. J Sci Ind Res 1981; 40:222.

[2] Geethamma VG, Mathew KT, Lakshminarayanan $\mathrm{R}$, Thomas S.Composite of short coir fibres and natural rubber: effect of chemical modification, loading and orientation of fibre. Polymer1998; 39(6):1483-91.

[3] Bisanda ETN, Ansell MP. Properties of sisal-CNSL composites.Journal of Materials Science 1992; 27:1690-700.

[4] Mukherjee PS, Satyanarayana KG. Structure and properties of some vegetable fibres, part Sisal fibre. Journal of Materials Science 1984; 19:3925 \pm 34 .

[5] Jayabal, S., Natarajan, U., (2010),'Influence of fibre parameters on tensile, flexural, and impact properties of nonwoven coir-polyester composites", Springer published online, Vol 15, pp.710-130.

[6] Paiva junior CZ,de carvalho LH,Forseca VM,Moneiro SN,(2004) polymer teste 23(2):135.

[7] Mariesidicula, Malhotra SK, Kuruvilla joseph, Sabu Thomas (2005) compositscience65:1087.

[8] Jacob Maya, Thomas Sabu, Varghese KT (2004) Composite science tech 64:965.

[9] Alsina OLS, de Carvalho LH, Romos Filho FG, (2007) Polym plast technology Eng. 46(5):520.

[10] Mehdi Tajvidi (2005) Inc. J Appl poly science 98:672. 